\title{
Proportional Assist Ventilation and Neurally Adjusted Ventilatory Assist
}

\author{
Robert M Kacmarek PhD RRT FAARC
}

\author{
Introduction \\ Theory of Operation \\ Proportional Assist Ventilation \\ Neurally Adjusted Ventilatory Assist \\ PAV and NAVA Versus Traditional Gas Delivery \\ Data Supporting the Use of PAV \\ PAV in Exercise \\ PAV During Sleep \\ Critically Ill Pediatric Patients \\ Noninvasive Ventilation \\ Invasive Mechanical Ventilation \\ Neurally Adjusted Ventilatory Support \\ Animal Data \\ Critically Ill Adults \\ Neonatal Application \\ PAV Versus NAVA \\ When to Use PAV and NAVA \\ Summary
}

Patient-ventilator synchrony is a common problem with all patients actively triggering the mechan-
ical ventilator. In many cases synchrony can be improved by vigilant adjustments by the managing
clinician. However, in most institutions clinicians are not able to spend the time necessary to ensure
synchrony in all patients. Proportional assist ventilation (PAV) and neurally adjusted ventilatory
assist (NAVA) were both developed to improve patient-ventilator synchrony by proportionally
unloading ventilatory effort and turning control of the ventilatory pattern over to the patient. This
paper discusses PAV's and NAVA's theory of operation, general process of application, and the
supporting literature. Key words: patient-ventilator synchrony; assisted ventilation; work of breathing;
diaphragmatic electromyogram; EMG. [Respir Care $2011 ; 56(2): 140-148$. C 2011 Daedalus Enterprises]

\section{Introduction}

One of the most challenging aspects of mechanical ventilation is the application of positive pressure to patients

Robert M Kacmarek PhD RRT FAARC is affiliated with the Department of Anesthesiology, Massachusetts General Hospital, and with Harvard Medical School, Boston, Massachusetts.

Dr Kacmarek has disclosed relationships with Covidien, Dräger, Newport, General Electric, Maquet, Hamilton, KCI, and Kimberly Clark. who are actively breathing. ${ }^{1}$ As discussed in other papers from this conference, patient-ventilator asynchrony is a

\footnotetext{
Dr Kacmarek presented a version of this paper at the 46th RESPIRATORY CARE Journal Conference, "Patient-Ventilator Interaction," held March 1921, 2010, in Cancún, Quintana Roo, Mexico.

Correspondence: Robert M Kacmarek PhD RRT FAARC, Respiratory Care, Ellison 401, Massachusetts General Hospital, 55 Fruit Street, Boston MA 02114. E-mail: rkacmarek@partners.org.
}

DOI: $10.4187 /$ respcare.01021 
very common problem..$^{2,3}$ Ventilator manufacturers have developed new ventilation modes that target both pressure and volume and have added adjuncts to pressure-targeted ventilation that are designed to improve synchrony: rise time and breath-termination (ie, cycle) criteria. ${ }^{4}$ Some ventilator manufacturers have tried to automate these functions to ensure that gas delivery changes as patient demand changes, ${ }^{4}$ but despite these new options, asynchrony is still a major problem.

In the United States 2 new modes of ventilatory support were recently introduced: proportional assist ventilation (PAV) ${ }^{5}$ and neurally adjusted ventilatory support (NAVA). ${ }^{6}$ Both of these modes are designed to improve patient-ventilator synchrony. ${ }^{7}$ Although each controls gas delivery by a different method, both are designed primarily to respond to changes in the patient's ventilatory demand and to decrease patient effort. ${ }^{7} \mathrm{PAV}$ is controlled by changes in the patient's work of breathing, ${ }^{5}$ and NAVA is controlled by changes in the electromyographic (EMG) activity of the diaphragm. ${ }^{6}$ It is critical to understand that with both PAV and NAVA the clinician does not set pressure, flow, volume or time: all those variables are under the complete control of the patient. Essentially, the ventilator proportionally unloads patient effort, in both PAV and NAVA, based on the setting of ventilator work: proportion (\%) unloaded by the ventilator (PAV), or $\mathrm{cm} \mathrm{H}_{2} \mathrm{O}$ pressure applied per millivolt of diaphragmatic EMG activity (NAVA). ${ }^{7}$

\section{Theory of Operation}

The pressure needed to ventilate can be totally provided by the patient, totally provided by the ventilator, or shared between the patient and the ventilator. Both PAV and NAVA are designed to ensure that the ventilating pressure (ie, work) is shared between the patient and ventilator in a manner intended to maximize synchrony. Both PAV and NAVA directly respond to the patient's ventilatory demand by providing either proportional unloading of work of breathing (PAV) or proportional unloading of the electrical activity of the diaphragm (NAVA). ${ }^{7}$ In both cases the actual ventilatory pattern assumed by the patient is totally controlled by the patient.

\section{Proportional Assist Ventilation}

The underling theory of operation for PAV is based on the equation of motion:

$$
\mathrm{P}_{\text {total }}=(\mathrm{V})(\mathrm{E})+(\dot{\mathrm{V}})(\mathrm{R})
$$

which states that the total pressure required to ventilate $\left(\mathrm{P}_{\text {total }}\right)$ is equal to tidal volume $(\mathrm{V})$ times elastance $(\mathrm{E})$ plus flow $(\dot{V})$ times airways resistance $(\mathrm{R})$. and

$$
\begin{array}{r}
\mathrm{P}_{\text {total }}\left(\mathrm{cm} \mathrm{H}_{2} \mathrm{O}\right)=(\mathrm{L})\left(\mathrm{cm} \mathrm{H}_{2} \mathrm{O} / \mathrm{L}\right)+ \\
(\mathrm{L} / \mathrm{min})\left(\mathrm{cm} \mathrm{H}_{2} \mathrm{O} / \mathrm{L} / \mathrm{min}\right)
\end{array}
$$

As noted above, in patients who are actively participating in ventilatory support $\mathrm{P}_{\text {total }}$ equals patient-generated muscular effort or pressure $\left(\mathrm{P}_{\text {mus }}\right)$ plus ventilator-generated pressure $\left(\mathrm{P}_{\text {vent }}\right)$, so the equation of motion can be rewritten as:

$$
\mathrm{P}_{\text {mus }}+\mathrm{P}_{\text {vent }}=(\mathrm{V})(\mathrm{E})+(\dot{\mathrm{V}})(\mathrm{R})
$$

All of today's ventilators can easily measure flow and thus can calculate volume on a moment-to-moment basis. ${ }^{4}$ The problem is to measure, in an ongoing manner, the $\mathrm{R}$ and $\mathrm{E}$ of the respiratory system. Some ventilator manufacturers have interposed an end-inspiratory pause of about $300 \mathrm{~ms}$ every 8 to 15 breaths, and from those measurements during those pauses they estimate the $\mathrm{R}$ and E. ${ }^{8}$ Others manufacturers have defined a process for the one-time estimation of $\mathrm{R}$ and $\mathrm{E}$, at the time PAV is initiated. Assuming that can be done accurately, the only variable in equation 1 that is not either directly measured or calculated is $\mathrm{P}_{\text {total }}$ Thus, the ventilator can calculate the pressure needed, at any given moment, to provide ventilation. If the clinician has set PAV at $60 \%$, the ventilator would provide $60 \%$ of the calculated pressure, the remaining pressure being left to the patient to generate. That is, on a breath-to-breath basis the ventilator applies the calculated amount of pressure needed to meet the flow and volume demand of the patient based on the set PAV percentage, leaving the remaining work to the patient. Exhalation occurs when flow decreases to a preset level. Additionally, as the patient's lung mechanics change, those ventilators that automatically measure $\mathrm{R}$ and $\mathrm{E}$ can adjust the amount of pressure needed to maintain the set PAV percentage.

Specifically, PAV improves patient-ventilator synchrony during the onset of inspiration, by matching the patient's inspiratory demand. That is, there is no limit to flow delivery, the ventilator responds to the patient's demand up to the capabilities of the ventilator, regardless of the PAV setting. This differs from pressure ventilation, in which flow will decelerate when airway pressure meets the target level. In PAV there is no pressure target; pressure will increase, as will flow, as patient demand increases. Cycling is improved because the ventilator adjusts flow during the end of inspiration the same as it does during the onset. Thus, as patient effort starts to decrease, flow delivery decreases, and when flow decreases to the cycling criterion, the ventilator transitions to exhalation. However, triggering is not directly improved with PAV, compared to 


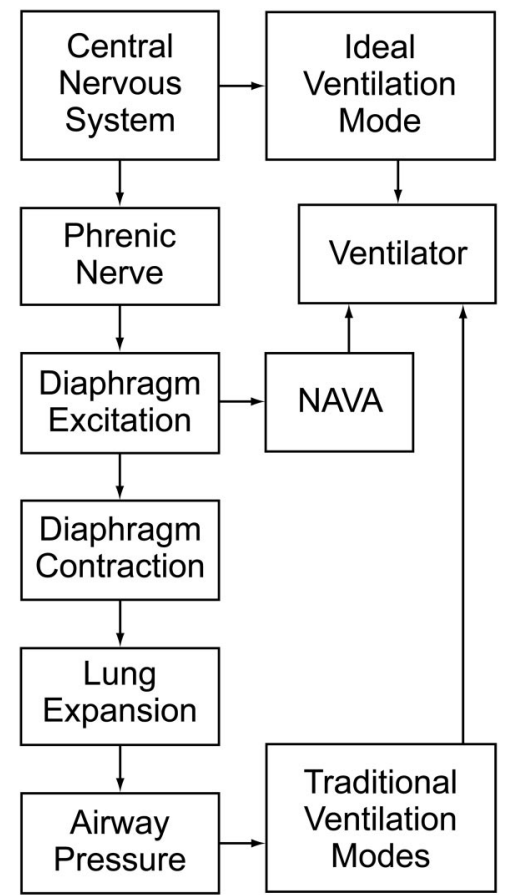

Fig. 1. Steps in the process of activating a ventilator breath. Neurally adjusted ventilatory assist ventilation modes are activated and controlled by diaphragm excitation. Proportional assist ventilation modes are activated by a change in airway pressure, flow, and volume. (Adapted from Reference 6.)

conventional ventilation. The patient still has to generate sufficient flow to trigger the ventilator. However, as discussed later, conventional modes may force a larger tidal volume than normal, causing air trapping and thus increasing the number of missed triggers.

\section{Neurally Adjusted Ventilatory Assist}

NAVA accomplishes the same goals as PAV but utilizes measurement of the diaphragmatic EMG signal to control gas delivery. ${ }^{6}$ This is accomplished by the placement of a specifically designed nasogastric tube that has a series of EMG electrodes near its distal end, positioned across the diaphragm. As illustrated in Figure 1, supporting ventilation based on the diaphragmatic EMG signal should greatly improve the response of the ventilator and synchrony, since the signal recognized is high up on the neural pathway controlling ventilation. ${ }^{7}$ What is set by the clinician is the pressure applied for each millivolt of EMG activity. Thus, similar to PAV, a portion of the ventilatory effort is proportionally provided by the ventilator, and the remainder by the patient. As EMG activity increases, pressure is applied during the inspiratory phase, and as the diaphragm relaxes, airway pressure decreases. Inspiration ends at a specific percentage of the peak EMG activity. Contrary to PAV, NAVA greatly improves triggering, since

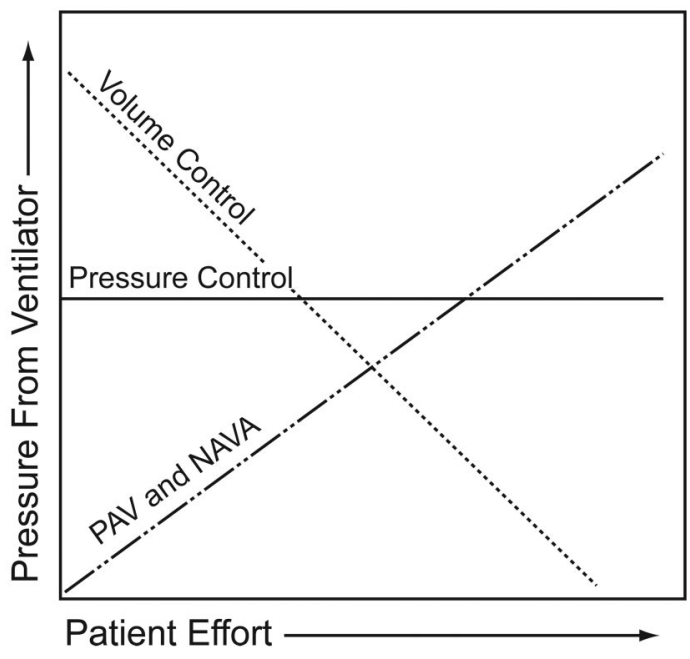

Fig. 2. Relationship between patient effort and ventilator pressure during various ventilation modes. During volume ventilation, patient effort and ventilator pressure are inversely related. During pressure ventilation, ventilator pressure in unaffected by patient effort. During proportional assist ventilation (PAV) and neurally adjusted ventilatory assist (NAVA), patient effort and ventilator pressure are directly related. (Adapted from Reference 5.)

gas delivery begins when the diaphragm is simulated, not as a result of flow in the airway. Thus, even in the presence of severe air trapping or large system leaks, triggering is not compromised.

\section{PAV and NAVA Versus Traditional Gas Delivery}

Figure 2 nicely illustrates the relationship between and the patient's effort or work of breathing and the ventilator pressure during various ventilation modes. ${ }^{1}$ During a specific breath, with all forms of volume ventilation there is an indirect relationship between patient effort $\left(\mathrm{P}_{\text {mus }}\right)$ and the pressure applied by the ventilator. Essentially, the more work assumed by the patient, the less work applied by the ventilator. This relationship creates difficult problems regarding synchrony, which can easily be illustrated with a lung model with proper setting of inspiratory demand. If demand is high and the lung model tidal volume is greater than the ventilator set tidal volume, no pressure above baseline will be applied to the lung.

In pressure-targeted ventilation, regardless of mode, ventilator work or applied pressure should be independent of $\mathrm{P}_{\text {mus }}$. That is, during a specific breath, a constant pressure should be applied to the airway during inspiration, no matter how much work or $\mathrm{P}_{\text {mus }}$ is generated by the patient. Of course, in patients with very high ventilatory demand, pressure may not be sustained since the ventilator may not always be able to meet patient flow demand.

In PAV and NAVA there is a direct relationship between the patient's effort $\left(\mathrm{P}_{\mathrm{mus}}\right)$ and ventilator pressure. 


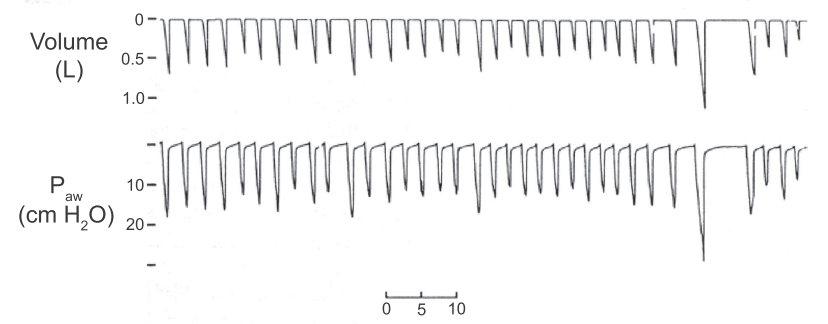

Fig. 3. Relationship between tidal volume and patient effort during both proportional assist ventilation (PAV) and neurally adjusted ventilatory assist (NAVA). In both PAV and NAVA the patient has total control over the ventilatory pattern and if the patient chooses to take a larger tidal volume the ventilator applies a greater pressure. (From Reference 5, with permission.)

As the patient's effort increases, the pressure applied by the ventilator increases, and as patient effort decreases, the pressure applied by the ventilator decreases. This is because the patient has complete control over their ventilatory pattern, and the ventilator is simply responding to the patient demand. Thus, tidal volume and respiratory rate can vary considerably from breath to breath, as illustrated in Figure 3. It is important again to remember that this variability is only under the control of the patient! What is essentially set in each of these modes is the slope of the curve representing the relationship between patient-generated and ventilator-generated pressure. That is, either a high ventilating pressure is applied for little patient effort, or a low ventilating pressure is applied for a high patient effort, or any settings in between.

\section{Data Supporting the Use of PAV}

Since PAV was first described in $1992,{ }^{5}$ many papers have addressed its use in various settings, including exercise, acute application in invasively and noninvasively ventilated patients, during sleep, and in neonates.

\section{PAV in Exercise}

Most of the data on PAV in exercise have been from patients with COPD, ${ }^{9-13}$ but there are also data from volunteers, ${ }^{14,15}$ and patients with idiopathic pulmonary fibrosis ${ }^{16}$ and obesity. ${ }^{17}$ In all the comparisons, regardless of the subjects' clinical status, PAV improved exercise capacity, compared to no support or to continuous positive airway pressure (CPAP) or pressure support ventilation (PSV). In 15 stable hypercapnic COPD patients undergoing 4 random endurance tests on a cycle ergometer at $80 \%$ of the patient's maximum work rate, PAV, PSV, and CPAP all increased endurance, compared to spontaneous breathing. However, the greatest increase was with PAV $(P<.05) .{ }^{10}$ Similarly, Dolmage et $\mathrm{al}^{9}$ observed a doubling of exercise tolerance with PAV plus CPAP, versus sham, in 10 patients with severe but stable COPD $(P<.05)$. In 10 patients with idiopathic pulmonary fibrosis, Moderno et $\mathrm{al}^{16}$ reported that PAV doubled exercise tolerance, compared to CPAP and sham $(P<.05)$. In 7 healthy volunteers at altitude, PAV reduced inspiratory pressure-time product to a greater extent than did PSV or sham $(P<.05)$. The benefits of PAV, compared to PSV or CPAP, appear to be a direct result of PAV's ability to unload ventilatory work proportionally, regardless of the PAV setting or the load applied to the subject. However, the impact of PAV on synchrony during exercise is unknown.

\section{PAV During Sleep}

A number of groups have used PAV to evaluate quality of sleep in patients requiring ventilatory support ${ }^{18}$ or the susceptibility of volunteers to periodic breathing. ${ }^{19-22}$ Prior data from Meza et $\mathrm{al}^{20}$ and Parthasarathy and Tobin ${ }^{23}$ clearly demonstrated that PSV induces arousals and awakenings due to central apneas in healthy volunteers ${ }^{20}$ and critically ill mechanically ventilated patients. ${ }^{23}$ This seems to be in part a result of PSV driving a level of ventilation during sleep that is consistent with that awake, causing a relative hypocapnia and, in the absence of backup control ventilation, apnea. The apnea threshold is a $\mathrm{P}_{\mathrm{CO}_{2}}$ change of 1.5$5.8 \mathrm{~cm} \mathrm{H}_{2} \mathrm{O}^{21}$

Bosma et al studied PAV versus PSV during sleep in critically ill patients. ${ }^{18}$ In 13 patients weaning from ventilatory support, PAV and PSV were applied randomly on subsequent nights. Each was set to unload $50 \%$ of patient work while awake. PAV was more effective in matching the patient's ventilatory requirements, and was associated with significantly less asynchrony and sleep disturbance (Table 1). Specifically, PAV was better able to adjust to the patient's decreased ventilatory drive during sleep and resulted in fewer episodes of periodic breathing.

\section{Critically Ill Pediatric Patients}

Although current versions of PAV are not recommended for use in neonates in the United States, there have been comparisons of PAV to other approaches to ventilatory support in these patients. ${ }^{24-27}$ Schulze et $\mathrm{al}^{24}$ randomly compared the physiologic efficacy and safety of PAV to pressure assist control ventilation and pressure synchronized intermittent mandatory ventilation in a series of 36 infants of birth weight 600-1200 g. Compared to pressure assist control ventilation and pressure synchronized intermittent mandatory ventilation, PAV maintained similar gas exchange with lower airway pressure and transpulmonary pressure $(P<.05)$, and the oxygenation index decreased $28 \%$ during PAV. PAV decreased thoracoabdominal asynchrony and chest-wall distortion, compared to CPAP, in a 
Table 1. Proportional Assist Ventilation and Pressure Support Ventilation During Sleep in 13 Patients Weaning From Ventilatory Support ${ }^{14}$

\begin{tabular}{|c|c|c|c|}
\hline & PAV & PSV & $P$ \\
\hline Minute ventilation (mean \pm SD L) & $13.5 \pm 2.3$ & $14.4 \pm 2.7$ & $<.05$ \\
\hline Tidal volume (mean $\pm \mathrm{SD}$ L) & $0.59 \pm 0.13$ & $0.63 \pm 0.13$ & $<.05$ \\
\hline Respiratory rate (mean \pm SD breaths/min) & $24.5 \pm 6.1$ & $24.2 \pm 5.3$ & NS \\
\hline $\mathrm{P}_{\mathrm{ETCO}_{2}}($ mean $\pm \mathrm{SD}$ mm Hg$)$ & $39.4 \pm 6.8$ & $37.3 \pm 5.3$ & $<.05$ \\
\hline Arousals/h (median, IQR) & $16(2-74)$ & $9(1-41)$ & $<.02$ \\
\hline Awakenings/h (median, IQR) & $3.5(0-24)$ & $5.5(1-24)$ & $<.05$ \\
\hline Rapid eye movement (\%, IQR) & $9(9-31)$ & $4(9-23)$ & $<.05$ \\
\hline Slow-wave sleep (\%, IQR) & $3(0-16)$ & $1(0-10)$ & $<.05$ \\
\hline Asynchrony events/h (mean $\pm \mathrm{SD})$ & $24 \pm 15$ & $53 \pm 59$ & $<.02$ \\
\hline $\begin{array}{l}\mathrm{PAV}=\text { proportional assist ventilation } \\
\mathrm{PSV}=\text { pressure support ventilation } \\
\mathrm{P}_{\mathrm{ETCO}_{2}}=\text { end-tidal partial pressure of carbon dioxide }\end{array}$ & & & \\
\hline
\end{tabular}

study by Musante et al, ${ }^{25}$ with 10 preterm infants. This was accomplished with airway pressure increases of only $3.8-$ $7.6 \mathrm{~cm} \mathrm{H}_{2} \mathrm{O}$ above CPAP settings. In a more recent study, Schulze et $\mathrm{al}^{27}$ demonstrated that PAV, compared to pressure-targeted ventilation, reduced mean airway pressure and peak airway pressure without a change in gas exchange. Although these positive studies appear in the literature, PAV is currently not recommended for patients less than $20 \mathrm{~kg}$. Part of this recommendation may be due to the inability of today's intensive-care ventilators to accurately measure lung mechanics in neonates. ${ }^{28}$

\section{Noninvasive Ventilation}

Numerous studies have evaluated PAV during noninvasive ventilation. ${ }^{29-39}$ Most of these comparisons were between PAV and PSV, 32-35,37-39 and in almost all of these comparisons the patients evaluated suffered from chronic respiratory failure and were in an exacerbation. The first randomized comparison between PAV and PSV enrolled 44 patients with COPD exacerbation. ${ }^{32}$ This was a physiologic comparison; the small number of subjects prevented comparison of intubation rate, mortality, or stay, but the patients managed with PAV had a lower refusal rate, a more rapid reduction in respiratory rate, and fewer complications. Similar finding were reported by Wysocki et al, ${ }^{34}$ Serra et al, ${ }^{35}$ Fernández-Vivas et al, ${ }^{37}$ and Winck et al.$^{38}$ In those studies gas exchange and respiratory pattern did not differ between PSV and PAV, but the PAV patients were more comfortable. PAV has also been shown to be essentially equivalent to PSV in stable patients with chronic ventilatory failure ${ }^{33}$ and patients with acute cardiogenic pulmonary edema. ${ }^{39}$ This lack of difference has not been fully explained, but it may be a result of all approaches to the application of noninvasive ventilation being compromised by the varying level of leak, which is still poorly compensated for by most ventilators. ${ }^{40}$

\section{Invasive Mechanical Ventilation}

PAV has been most widely studied during invasive mechanical ventilation. ${ }^{41-55}$ As with the evaluation of PAV in other settings, most of the comparisons have focused on the physiologic response when PSV is changed to PAV. In general, during invasive ventilation the change from PSV to PAV results in lower tidal volume, more rapid respiratory rate, lower peak airway pressure, and lower mean airway pressure, without significant changes in gas exchange or hemodynamics. ${ }^{41,44,45,48-53}$ A number of studies have evaluated the response of PSV and PAV to changes in the patient's lung mechanics. ${ }^{43,45,51}$ Both Ranieri et al ${ }^{43}$ and Grasso et $\mathrm{al}^{45}$ found no difference in patient work and effort between PSV and PAV as ventilatory load was increased, contrary to the finding of Kondili et al. ${ }^{51}$ The reason for this difference appears to be the ability of the PAV version used by Kondili to automatically assess lung elastance and resistance. In the Kondili ${ }^{51}$ trial the ventilator was able to update these measurements every $8-15$ breaths, whereas the PAV version used by Ranieri ${ }^{39}$ and $\mathrm{Grasso}^{45}$ required input of lung mechanics at the onset of ventilation and required interruption of ventilation and clinician remeasurement of lung mechanics if the values were to change. The current ability of some PAV systems to automatically and ongoingly measure lung mechanics ensures PAV's ability to consistently unload lung mechanics when changes occur in the patient's condition.

The best long-term evaluation of PAV versus PSV randomized their application for a 48 -hour period in a series of critically ill patients. ${ }^{53}$ Patients randomized had to be on controlled mechanical ventilation for 36hours, and had to be able to trigger the ventilator and maintain a minute volume of $>10 / \mathrm{min}$ and a $\mathrm{P}_{\mathrm{aO}_{2}}$ of $>60 \mathrm{~mm} \mathrm{Hg}$ and a pH $>7.30$ on an $\mathrm{F}_{\mathrm{IO}_{2}}$ of $<0.65$ and a total PEEP of $<15 \mathrm{~cm} \mathrm{H}_{2} \mathrm{O}$. In addition, the patients could not have severe hemodynamic instability, severe 
bronchospasm, or severe neurologic impairment. The percentage of patients who failed the transition to PAV or PSV differed $(P=.04): 11 \%$ failed PAV, and $22 \%$ failed PSV. In addition, the proportion of patients who developed asynchrony was greater with PSV (29\%) than with PAV $(5.6 \%)(P<.001)$. Similar results were observed by Giannouli et al, ${ }^{51}$ who compared the impact of different levels of PAV and PSV in a series of 14 ventilator-dependent patients. They found that at the minimum PAV and PSV levels no differences existed between the 2 modes. However, as the level of support for each mode increased, asynchrony increased. At the maximum settings, trigger asynchrony was markedly different: the ventilator response rate with PAV was $27.6 \pm 10.5 / \mathrm{min}$, versus $13.2+3.9 / \mathrm{min}$ with PSV $(P<.05)$. The primary reason for the asynchrony was missed triggers. This difference was a result of PSV forcing a larger tidal volume $(0.9+0.3 \mathrm{~L})$ than PAV $(0.51+0.16 \mathrm{~L})$, which caused air trapping and prevented normal triggering. Trigger synchrony is generally better in PAV because a large tidal volume is not forced on the patient. The current data on PAV essentially indicate it can sustain the same patients as PSV: those who can breathe spontaneously and manage their ventilatory drive normally. In addition, PAV can better adjust to changing lung mechanics and provide better synchrony than PSV. However, PAV, like all other conventional forms of ventilation, cannot compensate for nor overcome the effects of intrinsic PEEP. The asynchrony observed with intrinsic PEEP during conventional ventilation is still present in PAV. In addition, the PAV on some ventilators (but not on others) can compensate for leaks, so before use the ventilator's operational capabilities must be careful evaluated.

\section{Neurally Adjusted Ventilatory Support}

As discussed above, PAV and NAVA are essentially designed to accomplish the exact same goals, but via different mechanisms: PAV via ongoing assessment of lung mechanics and work of breathing, and NAVA via continuous diaphragmatic EMG.

\section{Animal Data}

In 3-kg rabbits, Allo et al ${ }^{56}$ found that NAVA could effectively unload respiratory muscles without increasing tidal volume. NAVA, compared to PSV, also decreased diaphragm electrical activity and transdiaphragmatic pressure-time product $(P<.05)$ in lung-injured rabbits, ${ }^{57}$ and reduced the incidence and severity of ventilator-induced lung injury in rabbits. ${ }^{58}$ However, similar to studies with other ventilation modes, the rabbits in the conventionalventilation arm were ventilated with volume-controlled ventilation and tidal volumes of $15 \mathrm{~mL} / \mathrm{kg}$. Tidal volumes during NAVA were about $5.5 \mathrm{~mL} / \mathrm{kg}$. In lung-injured rabbits, NAVA can be delivered noninvasively as effectively as in intubated rabbits despite large and varying leaks. ${ }^{59}$

\section{Critically Ill Adults}

A number of investigators have studied NAVA in critically ill adults. ${ }^{60-66}$ In a series of 15 adult critically ill patients, all with a $\mathrm{P}_{\mathrm{aO}} / \mathrm{F}_{\mathrm{IO}_{2}}<300 \mathrm{~mm} \mathrm{Hg}$, Brander et al determined an "adequate" level of NAVA. ${ }^{60}$ Adequate NAVA was identified by the slope change in airway pressure and tidal volume curves as NAVA was increased. The NAVA level that caused a slope decrease of the airwaypressure and tidal-volume curves was considered adequate. This physiologic response was compared to the response at lower (NAVA-low) and higher (NAVA-high) levels. At NAVA-adequate the medium esophageal pressure-time product and diaphragmatic EMG were decreased 47\%, compared to NAVA-low. At NAVA-high those variables were reduced by $74 \%$. Ventilatory parameters during the subsequent 3-hour follow-up period were the same on average as during titration: tidal volume $5.9 \mathrm{~mL} / \mathrm{kg}$ and respiratory rate 29 breaths/min. Gas exchange and hemodynamics remained unchanged.

Colombo et al $^{63}$ and Spahija et al ${ }^{65}$ compared NAVA to PSV in series of critically ill patients. Colombo matched the setting during NAVA and PSV by adjusting both to produce a tidal volume of $6-8 \mathrm{~mL} / \mathrm{kg}$. They compared NAVA and PSV at these settings and at settings 50\% higher and 50\% lower. At the initial and lowest settings they found no differences in gas exchange, ventilatory pattern, ventilatory assistance, or respiratory drive between the modes. But at the highest settings, tidal volume significantly increased, and ventilator response rate and peak diaphragmatic EMG significantly decreased during PSV, resulting in air trapping and cycling asynchrony. The asynchrony index was greater than $10 \%$ in 5 of the 6 patients studied during PSV, and in zero patients during NAVA. They concluded that even at the high settings NAVA avoided over-assisting, compared to PSV, by avoiding air trapping and cycling asynchrony.

Spahija et al ${ }^{65}$ reported similar finding in a series of 12 patients with COPD exacerbation. They evaluated 2 PSV and NAVA levels: for PSV the lowest pressure tolerated and that level plus $7 \mathrm{~cm} \mathrm{H}_{2} \mathrm{O}$; for NAVA the settings resulting in the same average peak pressures. At the lowest settings there were no differences, but at the highest setting tidal volumes were greater and ventilator response rates lower with PSV. The asynchrony index at the highest setting was $23 \pm 12 \%$ of breaths during PSV, but only $7 \pm 2 \%$ during NAVA $(P<.05)$. Spahija et al cited air trapping as the cause of the cycling asynchrony during PSV. 
The effect of PEEP titration during NAVA was recently reported by Passath et al, ${ }^{66}$ in a series of 20 patients, only one of whom had acute respiratory distress syndrome. Passath et al first adjusted NAVA to an adequate level, as previously defined, ${ }^{56}$ then titrated the PEEP up and down and evaluated the effect on respiratory drive. At adequate NAVA levels, increasing the PEEP reduced the ventilatory drive, and monitoring tidal volume divided by diaphragmatic EMG during PEEP changes identified the PEEP level at which tidal breathing occurs at a minimal EMG cost.

\section{Neonatal Application}

In neonates, NAVA has shown similar outcomes to those observed in adults. ${ }^{67-69}$ After the change to NAVA, tidal volume tends to decrease, respiratory rate to increase, and peak diaphragmatic EMG to decrease. In addition, despite the open ventilating system, triggering and cycling were still primarily neurally activated. Beck et al ${ }^{67}$ reported that in 936-g, 26-week neonates there were no significant differences between triggering and cycling delays during invasive and noninvasive NAVA. Bengtsson et al ${ }^{68}$ found, in a series of 21 mechanically ventilated children, ages 2 days to 15 years, that neural triggering occurred $68 \%$ of the time, and neural cycling $88 \%$ of the time. NAVA has only been available for about 18th months, so the literature on its effectiveness is limited, compared to PAV, and essentially no outcome data exist for either PAV or NAVA.

\section{PAV Versus NAVA}

As stated at the onset of this paper, PAV and NAVA are designed to achieve the same overall outcome, that is patient-driven ventilatory assist applied with improved patient-ventilator synchrony. Both modes are capable of achieving the goal, but there are some differences (Table 2). They manage ventilatory assist using different variables. PAV does not require additional hardware; NAVA requires the placement of a special nasogastric tube. NAVA can be used for invasive and noninvasive ventilation; PAV also can be used invasively and noninvasively, but is not available for both applications on all ventilators. NAVA can be applied to patients of any age group: premature neonates to adults, PAV is reserved for patients $>20 \mathrm{~kg}$. NAVA is not affected by leaks or intrinsic PEEP, since its function is based on diaphragm EMG signals. PAV is unable to adjust to intrinsic PEEP. In the presence of intrinsic PEEP, PAV functions the same as any other mode. Both PAV and NAVA improve patient-ventilator synchrony, but further study of both is needed to determine if either improves patient outcomes.
Table 2. Proportional Assist Ventilation Versus Neurally Adjusted Ventilatory Assist

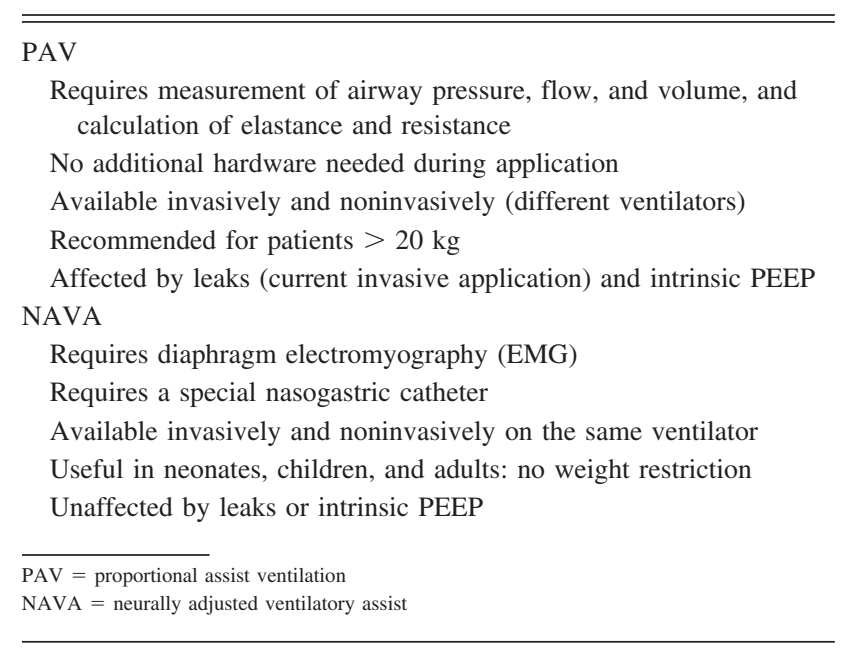

\section{When to Use PAV and NAVA}

Both PAV and NAVA are considered safe in patients who have intact ventilatory drive, so any patient who can be effectively managed with PSV can be effectively managed with PAV or NAVA. However, where PAV and NAVA may have an advantage over conventional modes is still unclear. Based on the limited data available, PAV and NAVA would be useful in any patient who has substantial asynchrony. In addition, PAV and NAVA can compensate for leaks, so use in neonates and pediatric patients with uncuffed airways may be an ideal indication. Finally, patients with chronic respiratory failure, all of whom have high levels of asynchrony, especially if ventilated longterm, may benefit from PAV or NAVA.

Neither PAV nor NAVA would seem particularly useful in patients requiring short-term ventilation, and no data are available on PAV and NAVA in surgical patients, probably because their ventilatory course is usually short and uncomplicated. Obviously, any patient who requires substantial sedation or has marked hemodynamic compromise would not be appropriate for PAV or NAVA.

\section{Summary}

Both PAV and NAVA improve patient-ventilator synchrony and allow the patient to establish a ventilatory pattern consistent with the patient's ventilatory demands. In general, this leads to a more rapid and shallow breathing pattern than is selected by clinicians. Part of the difficulty in clinicians' accepting PAV and NAVA is the fact that it is the patient that controls their own ventilatory patternnot the clinician. Additional data are needed before indications for PAV and NAVA can be clearly defined and we determine if PAV or NAVA have any outcome benefit. 


\section{REFERENCES}

1. Hess DR, Kacmarek RM. Essentials of respiratory care. New York: McGraw-Hill; 2002:105-113.

2. Epstein SK. How often does patient-ventilator asynchrony occur and what are the consequences? Respir Care 2011;56(1):25-35; discussion 35-38.

3. de Wit MD. Monitoring of patient-ventilator interaction at the bedside. Respir Care 2011;56(1):61-68; discussion 68-72.

4. Kacmarek RM, Chipman D. Basic principles of ventilator machinery. In: Tobin MJ (editor). Principles and practice of mechanical ventilation, 2nd edition. New York: McGraw-Hill; 2006:53-96.

5. Younes M. Proportional assist ventilation, a new approach to ventilatory support. Theory. Am Rev Respir Dis 1992;145(1):114-120.

6. Sinderby C, Navalesi P, Beck J, Skrobik Y, Comtois N, Friberg S, et al. Neural control of mechanical ventilation in respiratory failure. Nature Med 1999:5(12):1433-1436.

7. Sinderby C, Beck J. Proportional assist ventilation and neurally adjusted ventilatory assist - better approaches to patient ventilator synchrony? Clin Chest Med 2008;29(2):329-342.

8. Younes M, Kun J, Masiowski B, Webster K, Roberts D. A method for noninvasive determination of inspiratory resistance during proportional assist ventilation. Am J Respir Crit Care Med 2001;163(4): 829-839.

9. Dolmage TE, Goldstein RS. Proportional assist ventilation and exercise tolerance in subjects with COPD. Chest 1997;111(4):948-954.

10. Bianchi L, Foglio K, Pagani M, Vitacca M, Rossi A, Ambrosino N. Effects of proportional assist ventilation on exercise tolerance in COPD patients with chronic hypercapnia. Eur Respir J 1998;11(2): 422-427.

11. Hernandez P, Maltais F, Gursahaney A, Leblanc P, Gottfried SB. Proportional assist ventilation may improve exercise performance in severe chronic obstructive pulmonary disease. J Cardiopulm Rehabil 2001;21(3):135-142.

12. Hawkins P, Johnson LC, Nikoletou D, Hamnegard C-H, Sherwood R, Polkey MI, Moxham J. Proportional assist ventilation as an aid to exercise training in severe chronic obstructive pulmonary disease. Thorax 2002;57(10):853-859.

13. Poggi R, Appendini L, Polese G, Colombo R, Donner CF, Rossi A. Noninvasive proportional assist ventilation and pressure support ventilation during arm elevation in patients with chronic respiratory failure: a preliminary, physiologic study. Respir Med 2006;100(6): 972-979.

14. Kleinsasser A, Von Goedecke A, Hoermann C, Maier S, Schaefer A, Keller C, Loeckinger A. Proportional assist ventilation reduces the work of breathing during exercise at moderate altitude. High Alt Med Biol 2004;5(4):420-428.

15. Wysocki M, Meshaka P, Richard JC, Similowski T. Proportionalassist ventilation compared with pressure-support ventilation during exercise in volunteers with external thoracic restriction. Crit Care Med 2004;32(2):409-414.

16. Moderno EV, Yamaguti WP, Schettino GP, Kairalla RA, Martins MA, Carvalho CR, Carvalho CR. Effects of proportional assisted ventilation on exercise performance in idiopathic pulmonary fibrosis patients. Respiratory Med 2010;104:134-141.

17. Dreher M, Kabitz HJ, Burgardt V, Walterspacher S, Windisch W. Proportional assist ventilation improves exercise capacity in patients with obesity. Respiration 2010;80(2):106-111.

18. Bosma K, Ferreyra G, Ambrogio C, Pasero D, Mirabella L, Braghiroli A, et al. Patient-ventilator interaction and sleep in mechanically ventilated patients: pressure support versus proportional assist ventilation. Crit Care Med 2007;35(4):1048-1054.

19. Meza S, Younes M. Ventilatory stability during sleep studied with proportional assist ventilation (PAV). Sleep 1996;19(10 Suppl):S164S166.
20. Meza S, Giannouli E, Younes M. Control of breathing during sleep assessed by proportional assist ventilation. J Appl Physiol 1998; 84(1):3-12.

21. Meza S, Mendez M, Ostrowski M, Younes M. Susceptibility to periodic breathing with assisted ventilation during sleep in normal subjects. J Appl Physiol 1998;85(5):1929-1940.

22. Alexopoulou C, Kondili E, Vakouti E, Klimathianaki M, Prinianakis G, Georgopoulos D. Sleep during proportional-assist ventilation with load-adjustable gain factors in critically ill patients. Intensive Care Med 2007;33(7):1139-1147.

23. Parthasarathy S, Tobin MJ. Effect of ventilatory mode on sleep quality in critically ill patients. Am J Respir Crit Care Med 2002; 166(11):1423-1429.

24. Schulze A, Gerhardt T, Musante G, Schaller P, Claure N, Everett R, et al. Proportional assist ventilation in low birth weight infants with acute respiratory disease: a comparison to assist/control and conventional mechanical ventilation. J Pediatr 1999;135(3):339-344.

25. Musante G, Schulze A, Gerhardt T, Everett R, Claure N, Schaller P, Bancalari E. Proportional assist ventilation decreased thoracoabdominal asynchrony and chest wall distortion in preterm infants. Pediatr Res 2001;49(2):175-180

26. Rieger-Fackeldey E, Hofmiller A, Schulze A. Antecedents of respiratory pauses in extremely low birth weight infants supported by proportional assist ventilation. J Matern Fetal Neonatal Med 2006; 19(1):49-55.

27. Schulze A, Rieger-Fackeldey E, Gerhardt T, Claure N, Everett R, Bancalari E. Randomized crossover comparison of proportional assist ventilation and patient-triggered ventilation in extremely low birth weight infants with evolving chronic lung disease. Neonatology 2007;92(1):1-7.

28. Chipman D, Marchase A, Kacmarek RM. Measurement of respiratroy mechanics by ICU ventilators (abstract). Respir Care 2008; 53(11): 1588 .

29. Patrick W, Webster K, Ludwig L, Roberts D, Wiebe P, Younes M. Noninvasive positive- pressure ventilation in acute respiratory distress without prior chronic respiratory failure. Am J Respir Crit Care Med 1996;153(3):1005-1011.

30. Polese G, Vitacca M, Bianchi L, Rossi A, Ambrosino N. Nasal proportional assist ventilation unloads the inspiratory muscles of stable patients with hypercapnia due to COPD. Eur Respir J 2000; 16(3):491-498.

31. Vitacca M, Clini E, Pagani M, Bianchi L, Rossi A, Ambrosino N. Physiologic effects of early administered mask proportional assist ventilation in patients with chronic obstructive pulmonary disease and acute respiratory failure. Crit Care Med 2000;28(6):1791-1797.

32. Gay PC, Hess DR, Hill NS. Noninvasive proportional assist ventilation for acute respiratory insufficiency. Comparison with pressure support ventilation Am J Respir Crit Care Med 2001;164(9):1606-1611.

33. Porta R, Appendini L, Vitacca M, Bianchi L, Donner CF, Pogg R, Ambrosino N. Mask proportional assist vs. pressure support ventilation in patients in clinically stable condition with chronic ventilatory failure. Chest 2002;122(2):479-488.

34. Wysocki M, Richard J-C, Meshaka P. Noninvasive proportional assist ventilation compared with noninvasive pressure support ventilation in hypercapnic acute respiratory failure. Crit Care Med 2002; 30(2):323-329.

35. Serra A, Polese G, Braggion C, Rossi A. Non-invasive proportional assist and pressure support ventilation in patients with cystic fibrosis and chronic respiratory failure. Thorax 2002;57(1):50-54.

36. Hart N, Hunt A, Polkey MI, Fauroux B, Lofaso F, Simonds AK. Comparison of proportional assist ventilation and pressure support ventilation in chronic respiratory failure due to neuromuscular and chest wall deformity. Thorax 2002;57(11):979-981. 
37. Fernández-Vivas M, Caturla-Such J, González de la Rosa J, AcostaEscribano J, Alvarez-Sánchez B, Cánovas-Robles J. Noninvasive pressure support versus proportional assist ventilation in acute respiratory failure. Intensive Care Med 2003;29(7):1126-1133.

38. Winck JC, Vitacca M, Morais A, Barbano L, Porta R, Teixeira-Pinto A, Ambrosino N. Tolerance and physiologic effects of nocturnal mask pressure support vs. proportional assist ventilation in chronic ventilatory failure. Chest 2004;126(2):382-388.

39. Rusterholtz T, Bollaert P-E, Feissel M, Romano-Girard F, Harlay M-L, Zaehringer $\mathrm{M}$, et al. Continuous positive airway pressure vs proportional assist ventilation for noninvasive ventilation in acute cardiogenic pulmonary edema. Intensive Care Med 2008;34(5):840-846.

40. Ferreira JC, Chipman DW, Hill NS, Kacmarek RM. Bilevel vs. ICU ventilators providing noninvasive ventilation: effect of system leaks: a COPD lung model comparison. Chest 2009;136(2):448-456.

41. Ranieri VM, Giuliani R, Mascia L, Grasso S, Petruzzelli V, Puntillo $\mathrm{N}$, et al. Patient-ventilator interaction during acute hypercapnia: pressure-support vs. proportional-assist ventilation. J Appl Physiol 1996; 81(1):426-326.

42. Navalesi P, Hernandez P, Wongsa A, Laporta D, Goldberg P, Gottfried SB. Proportional assist ventilation in acute respiratory failure: effects on breathing pattern and inspiratory effort. Am J Respir Crit Care Med 1996;154(5):1330-1338.

43. Ranieri VM, Grasso S, Mascia L, Martino S, Tommasco F, Brienza A, Giuliani R. Effects of proportional assist ventilation on inspiratory muscle effort in patients with chronic obstructive pulmonary disease and acute respiratory failure. Anesthesiology 1997;86(1):79-91.

44. Wrigge H, Golisch W, Zinserling J, Sydow M, Almeling G, Burchardi $\mathrm{H}$. Proportional assist versus pressure support ventilation: effects on breathing pattern and respiratory work of patients with chronic obstructive pulmonary disease. Intensive Care Med 1999; 25(8):790-798.

45. Grasso S, Puntillo F, Mascia L, Ancona G, Fiore T, Bruno F, et al. Compensation for increase in respiratory workload during mechanical ventilation. Am J Respir Crit Care Med 2000;161(3 Pt 1):819-826.

46. Du H-L, Ohtsuji M, Shigeta M, Chao DC, Sasaki K, Usuda Y, Yamada Y. Expiratory asynchrony in proportional assist ventilation. Am J Respir Crit Care Med 2002;165(7):972-977.

47. Vitacca M. New things are not always better: proportional assist ventilation vs. pressure support ventilation. Intensive Care Med 2003; 29(7):1038-1040.

48. Passam F, Hoing S, Prinianakis G, Siafakas N, Milic-Emili J, Georgopoulos D. Effect of different levels of pressure support and proportional assist ventilation on breathing pattern work of breathing and gas exchange in mechanically ventilated hypercapnic COPD patients with acute respiratory failure. Respiration 2003;70(4):355-361.

49. Delaere S, Roeseler J, D'hoore W, Matte P, Reynaert M, Jolliet P, et al. Respiratory muscle workload in intubated, spontaneously breathing patients without COPD: pressure support vs. proportional assist ventilation. Intensive Care Med 2003;29(6):949-954.

50. Varelmann D, Wrigge H, Zinserling J, Muders T, Hering R, Putensen C. Proportional assist versus pressure support ventilation in patients with acute respiratory failure: cardiorespiratory responses to artificially increased ventilatory demand. Crit Care Med 2005;33(9):1968-1975.

51. Kondili E, Prinianakis G, Alexopoulou C, Vakouti E, Kilmanthianaki M, Georgopoulos D, Respiratory load compensation during mechanical ventilation - proportional assist ventilation with load -adjustable gain factors versus pressure support. Intensive Care Med 2006;32(5):692-699.

52. Kondili E, Xirouchaki N, Vaporidi K, Klimathianaki M, Georgopoulos D. Short-term cardiorespiratory effects of proportional assist and pressure-support ventilation in patients with acute lung injury/ acute respiratory distress syndrome. Anesthesiology 2006;105(4): 703-308.
53. Xirouchaki N, Kondili E, Vaporidi K, Xirouchakis G, Klimathianaki M, Gavriilidis G, et al. Proportional assist ventilation with loadadjustable gain factors in critically ill patients: comparison with pressure support. Intensive Care Med 2008;34(11):2026-2034.

54. Xirouchaki N, Kondili E, Klimathianaki M, Georgopoulos D. Is proportional-assist ventilation with load-adjustable gain factors a user-friendly mode? Intensive Care Med 2009;35(9):1599-1603.

55. Giannouli E, Webster K, Roberts D, Younes M. Response of ventilator-dependent patients to different levels of pressure support and proportional assist ventilation. Am J Respir Crit Care Med 1999; 159(6): 1716-1725.

56. Allo J-C, Beck JC, Brander L, Brunet F, Slutsky AS, Sinderby CA. Influence of neurally adjusted ventilatory assist and positive endexpiratory pressure on breathing pattern in rabbits with acute lung injury. Crit Care Med 2006;34(12):2997-3004.

57. Beck J, Campoccia F, Allo JC, Brander L, Brunet F, Slutsky AS, Sinderby C. Improved synchrony and respiratory unloading by neurally adjusted ventilatory assist (NAVA) in lung-injured rabbits. Pediatr Res 2007;61(3):289-294.

58. Brander L, Sinderby C, Lecomte F, Leong-Poi H, Bell D, Beck J, et al. Neurally adjusted ventilatory assist decreases ventilator-induced lung injury and non-pulmonary organ dysfunction in rabbits with acute lung injury. Intensive Care Med 2009;35(11):1979-1989.

59. Beck J, Brander L, Slutsky AS, Reilly MC, Dunn MS, Sinderby C. Noninvasive neurally adjusted ventilatory assist in rabbits with acute lung injury. Intensive Care Med 2008;34(2):316-323.

60. Brander L, Leong-Poi H, Beck J, Brunet F, Hutchison SJ, Slutsky AS, Sinderby C. Titration and implementation of neurally adjusted ventilatory assist in critically ill patients. Chest 2009;135(3):695-703.

61. Lecomte F, Brander L, Jalde F, Beck J, Qui H, Elie C, et al. Physiological response to increasing levels of neurally adjusted ventilatory assist (NAVA). Respir Physiol Neurobiol 2009;166(2):117-124.

62. Jalde FC, Almadhoob AR, Beck J, Slutsky AS, Dunn MS, Sinderby C. Neurally adjusted ventilatory assist and pressure support ventilation in small species and the impact of instrumental dead space. Neonatology 2010;97(3):279-285.

63. Colombo D, Cammarota G, Bergamaschi V, De Lucia M, Della Corte F, Navalesi P. Physiologic response to varying levels of pressure support and neurally adjusted ventilatory assist in patients with acute respiratory failure. Intensive Care Med 2008;34(11):1010-2018.

64. Schmidt M, Demoule A, Cracco C, Gharbi A, Fiamma MN, Straus C, et al. Neurally adjusted ventilatory assist increased respiratory variability and complexity in acute respiratory failure. Anesthesiology 2010;112(3):670-681.

65. Spahija J, de Marchie M, Albert M, Bellemare P, Delisle S, Beck J, Sinderby C. Patient-ventilator interaction during pressure support ventilation and neurally adjusted ventilatory assist. Crit Care Med 2010;38(2):518-526.

66. Passath C, Takala J, Tuchscherer D, Jakob SM, Sindreby C, Brander L. Physiological response to changing positive end-expiratory pressure during neurally adjusted ventilatory assist in sedated, critically ill adults. Chest 2010;138(3):578-587.

67. Beck J, Reilly M, Grasselli G, Mirabella L, Slutsky AS, Dunn MS, Sinderby C. Patient-ventilator interaction during neurally adjusted ventilatory assist in low birth weight infants. Pediatr Res 2009;65(6): 663-668.

68. Bengtsson JA, Edberg KE. Neurally adjusted ventilatory assist in children: an observational study. Pediatr Crit Care Med 2010;11(2): 253-257.

69. Breatnach C, Conlon NP Stack M, Healy M, O’Hare BP. A prospective crossover comparison of neurally adjusted ventilatory assist and pressure-support ventilation in a pediatric and neonatal intensive care unit population. Pediatr Crit Care Med 2010;11(1):7-11. 


\section{Discussion}

MacIntyre: You seemed to downplay what I thought was the fundamental difference between PAV and NAVA, which is in the triggering process. If you're cycling off of an EMG signal, you'll have a much more sensitive and responsive cycle than if you're cycling off of an airway-circuit signal. Am I missing something? It seems that's the fundamental difference between PAV and NAVA.

Kacmarek: We have no head-tohead comparison between the two. Theoretically, that should be the case. Auto-PEEP creates a problem for PAV, but if auto-PEEP isn't present and we're not forcing a pattern that increases the probability of air-trapping in somebody without chronic lung disease, we should not see a significant difference in trigger response. The results of the comparisons with pressure-support, although not perfect, clearly indicated a marked reduction in the number of missed triggers when PAV was compared to pressure-support. With NAVA, some $60 \%$ of the time it's a neural trigger, but some $30 \%$ of the time it's still a pneumatic trigger that is activated as the patient inspires.

Neil, you may well be right, but I don't know of any data to support it except for the patient with autoPEEP at baseline-a patient with chronic pulmonary disease. If we eliminate patients with chronic pulmonary disease, my guess is that triggering with PAV and NAVA is probably relatively similar. A wellfunctioning ventilator responds in about 60-80 milliseconds. With NAVA you'd expect trigger response to be reduced to somewhere in the range of 10-20 milliseconds. Whether that difference has a clinical impact in patients without auto-PEEP is unknown.
Younes:* For any trigger you have to choose a threshold: you can't just say any time you see an increase in $\mathrm{E}_{\mathrm{di}}$ [electrical activity of the diaphragm] or in this or that, go ahead and trigger. I'm very surprised to see that $30 \%$ of the breaths are not triggered by NAVA, because if NAVA doesn't trigger on a breath it means that the whole rising phase was missed. Not just the beginning of it: the whole amplitude. So I'm concluding that you have to set the threshold so high because of the noise at baseline.

Kacmarek: There's not a lot of NAVA trials, but these trials indicate the same thing: that $60-70 \%$ of the inspiratory efforts are $\mathrm{E}_{\mathrm{di}}$-triggered.

Younes: But missing the whole breath?

Kacmarek: If the breath is not triggered by $\mathrm{E}_{\mathrm{di}}$ activity, it is triggered by a pneumatic trigger, similar to all other modes.

Younes: With respect to the autoPEEP, however, I fully agree with you. In patients who have a lot of autoPEEP it may be a problem ventilating them with PAV. But not all auto-PEEP is a problem: it has to be a pretty substantial auto-PEEP, like 7-10 $\mathrm{cm} \mathrm{H}_{2} \mathrm{O}$ in a patient who cannot generate much pressure because of muscle weakness. And with PAV you know $\mathrm{P}_{\text {mus }}$ [inspiratory muscle pressure] and you can trigger off the $\mathrm{P}_{\text {mus }}$. You don't need to wait until the flow goes over zero; it's just that ventilator companies haven't done it, but the mechanism is there to do it.

Kacmarek: I'd agree with you theoretically, but there are no data to imply that the trigger will be better if there is no auto-PEEP.

\footnotetext{
* Magdy Younes MD FRCP(C) PhD, Department of Medicine, University of Manitoba, Winnipeg, Manitoba, Canada.
}

Epstein: Yesterday morning Bill [Hurford] raised the issue that we hadn't talked much about the airways. We now have data that endotracheal tubes are often a lot narrower than you think they are, based on what they look like in the package, and I wonder if that would create the same problem in triggering that NAVA theoretically should overcome? I know there are no data, but it's just a thought. Also, the data you showed on the $30 \%$ pneumatic trigger: was that just neonates?

Kacmarek: No, there are similar data in adults. Remember, with PAV, depending on the company, if the machine has the capability of reassessing lung mechanics every $5-15$ breaths, it can adjust to changing airways resistance and apply higher airway pressure. You also must indicate the size of the endotracheal tube.

Epstein: I'm thinking about triggering: not just the delivery of pressure.

Parthasarathy: Are there any data from patients with unilateral diaphragmatic paralysis on NAVA? Patients with unilateral diaphragmatic paralysis seem to be common in long-term acute-care facilities.

Kacmarek: I did not come across any data, but as long as one diaphragm was firing and you could measure the EMG, I would think it would work. But that's speculation. I've used NAVA on myself, and I've seen it used in other institutions, but we have not used NAVA at Massachusetts General Hospital, so I don't have substantial personal experience.

Parthasarathy: So that might be a limitation with folks with bilateral diaphragmatic paralysis. The other thing that I notice in the ICU nowadays is that everybody has 2 tubes: a Dobhoff and a nasogastric tube. The nasogastric tube is to decompress the stomach, and the Dobhoff tube is directed into the ileum for feeding. 
Kacmarek: Those function as a standard nasogastric tube. They do have a lumen so they can be used as a nasogastric tube.

Younes: Do you know how NAVA deals with non-respiratory activity of the diaphragm. The diaphragm muscle contributes to several activities, including vomiting and coughing. How does NAVA respond to that?

I don't know, but I assume just like conventional ventilation modes. I have seen examples of hiccupping causing a bizarre breath.

Younes: But how about vomiting, for example, where the diaphragm is contracting violently to get the food out?

Kacmarek: I don't know. I know it has an algorithm to deal with the heart rate, but I don't know how it deals with something like vomiting.

Sassoon: If you have a problem with vomiting or coughing, wouldn't something like that trigger the backup from the pneumatic system?

Younes: No, because vomiting doesn't generate any negative pressure in the chest that would pull in air and trigger the ventilator.

Sassoon: I wonder how the backup would work under that condition.

Kacmarek: Both PAV and NAVA have backup ventilation. If apnea occurs for a number of seconds, both convert to backup ventilation.

Sassoon: How do you know that the catheter is in the correct position?

Kacmarek: When you put the catheter in, one of the Servo-i screens is for catheter placement. There are 4 ECG signals and an EMG signal displayed on the screen. The middle 2 ECG signals should be predominant if the catheter is placed equidistant above and below the diaphragm.

Sassoon: Will the EMG signal be influenced by the ever-changing environment, for example from the $60-\mathrm{Hz}$ electrical interference?

Kacmarek: I don't know, but I assume they've filtered that type of interference. Whether they've been successful, experience will tell.

Sassoon: How long do the catheters last? When do you have to change?

Kacmarek: There is no recommendation to change the catheter on a regular basis. I think it generally functions well for about 3-5 days, but I don't have details.

Sassoon: In the papers you reviewed, what was the longest duration a patient received ventilatory support with NAVA?

Kacmarek: They were all shortterm: hours to days. None of the NAVA studies lasted for more than a few hours. With PAV, application was considerably longer in many studies, particularly with NIV [noninvasive ventilation]. In critically ill intubated patients the longest reported application of PAV was 2 days.

Kallet: You talked about the advantages of NAVA over PAV with someone with COPD. It occurred to me, if you have someone with COPD who's in distress and you're triggering the ventilator off the neural signal, as they become more hyperinflated, then I can see a possible runaway until their lungs explode. At least with pressure triggering, at a certain point the threshold load is so great that you can't trigger, whereas with this I can just see the lungs getting bigger and bigger.

Kacmarek: Let me ask you: do breathing spontaneously patients with COPD breathe with a pattern that causes continually increasing hyperinflation and then their lungs explode?

Kallet: No.

Kacmarek: There should be no difference with PAV or NAVA. Remember, neither of these modes forces a ventilatory pattern; the patient chooses the $\mathrm{V}_{\mathrm{T}}$ [tidal volume]. If their $\mathrm{V}_{\mathrm{T}}$ before applying NAVA or PAV is $300 \mathrm{~mL}$, it shouldn't change when NAVA or PAV is applied: it should simply require less work. It doesn't change the $\mathrm{V}_{\mathrm{T}}$ or the respiratory rate: it simply makes it easier to breathe at the patient's desired $\mathrm{V}_{\mathrm{T}}$ and rate.

Kallet: Right, but my point is that if the gain is based on the strength of contraction-talking about a patient who gets in distress-the stronger the contraction, then the more support it gives, and if the person is more and more hyperinflated and the brain is driving the muscle to contract...

Kacmarek: But what's driving the muscle to contract? The amount of effort it has to produce in order to move a volume.

Kallet: And also other inputs: if they're retaining $\mathrm{CO}_{2}$, if their blood pressure is dropping, or if they have dyspnea. It's a complex thing. I could just see that you could get runaway. The ventilator is still driven by a neural signal, even if the diaphragm can't generate any force. The other thing is that as the diaphragm is becoming flattened, you might lose the signal: that might take care of it. It's complicated. The fact that it's neurally triggered doesn't necessarily make this.

Kacmarek: All I can say is that in every report on PAV or NAVA so far, no patient with COPD has exploded. 
Kallet: But that's with 30-minute or 4-hour trial periods. I'm not exactly impressed by that endorsement.

Kacmarek: That's not true. We have used PAV for weeks in patients with severe COPD exacerbations. The phenomenon you mentioned has never been described in the literature, nor have we observed it.

Younes: In partial support of what Rich is saying, people with severe COPD when they exercise-in other words when their respiratory drive goes up a lot-their FRC [functional residual capacity] goes up, and that is the mechanism of exercise limitation in patients with severe COPD. The brain keeps activating the diaphragm, but there's no time to exhale. That is without any additional support. So if there's something on the outside that just keeps pushing on top of that, then there may be a problem of barotrauma. Whether that can happen in an ICU setting is something else, but the brain is not smart enough in these people to know to stop increasing the diaphragm activation when the drive goes up.

Epstein: So this would be the one instance where asynchrony is good?

Younes: Yes.

Parthasarathy: But is it also not true that this was a conceptual model that Rolf Hubmayr proposed of maximal flow versus lung volume? Eventually you'll be pushed to a lung volume where your $\dot{\mathrm{V}}_{\max }$ reaches a point where the patient would be able to exhale, which is what we're doing with every patient with COPD. The reason they're able to still ventilate on the ventilator is that we' re pushing them on a better point on their $\dot{\mathrm{V}}_{\text {max }}$-to-EELV [end-expiratory lung volume] relationship.

Kacmarek: We just don't see this happening when we ventilate patients, whether we ventilate invasively or noninvasively, regardless of mode. It just doesn't happen.

Parthasarathy: The problem is that we're not able to accurately measure EELV in our ICU patients.

Kacmarek: Sure.

Parthasarathy: In our weaning trials what we noticed was that in every COPD patient, if we indexed their $\mathrm{P}_{\mathrm{es}}$ [esophageal pressure] tracing as a poor man's measure of EELV, anyone who's been disconnected immediately their end-expiratory $\mathrm{P}_{\mathrm{es}}$ data point drops, so the lung volume drops almost instantaneously and we've had difficulty publishing it, because it's the poor man's estimation of EELV.

Kacmarek: Did they all drop in association with a change in minute volume? I would expect, in many patients, that when ventilatory support is discontinued, overall minute ventilation also decreases, which I expect decreases auto-PEEP.

Parthasarathy: I don't know about the minute ventilation, but it was uncanny how-we have some data suggesting that the ones who are successfully liberated drop their endexpiratory $\mathrm{P}_{\mathrm{es}}$ more rapidly than the ones who drop it more slowly, but then their $\mathrm{P}_{\mathrm{es}}$ actually goes up, because it's a also function of abdominal muscle activity. That's why when Amal Jubran published her data ${ }^{1,2}$ showing where end-expiratory $\mathrm{P}_{\mathrm{es}}$ is going, it's extremely likely that some of that is dynamic hyperinflation. But there was an initial instantaneous momentary drop in $\mathrm{P}_{\mathrm{es}}$ in the first minute, and that was different between weaning failures and weaning successes. It's such a difficult measure to interpret and publish as an expression of lung volume. We don't have an accurate, reliable, reproducible, instantaneous measure of EELV in ventilated patients.
1. Jubran A, Tobin MJ. Passive mechanics of lung and chest wall in patients who failed or succeeded in trials of weaning. Am J Respir Crit Care Med 1997;155(3):916921.

2. Jubran A, Tobin MJ. Pathophysiologic basis of acute respiratory distress in patients who fail a trial of weaning from mechanical ventilation. Am J Respir Crit Care Med 1997;155(3):906-915.

Younes: If you do it with the plateau pressure, you know what the endexpiratory pressure is, and then subtract the $\mathrm{V}_{\mathrm{T}}$ divided by compliance. That will give you the elastic recoil at EELV. If you do a pressure/volume curve for the patient, you can read off the EELV.

Parthasarathy: But those are spontaneously breathing patients.

Younes: But you can still get the pressure/volume curve at different $\mathrm{V}_{\mathrm{T}}$, and then you know the plateau pressure at that volume, and then you subtract the $\mathrm{V}_{\mathrm{T}}$ from it. That gives you the end-expiratory volume.

Branson: I don't have that much experience because surgical patients don't do very well on NIV, but all the problems of triggering and cycling with NIV would seem to make NAVA the perfect place. How much better would NAVA have to be than regular ventilation to convince you to put that tube down the patient's nose before you start NIV? It would be invasive monitoring with NIV.

Kacmarek: It would have to at least decrease the intubation rate. I assume it would not be easy to use NAVA during NIV. Taking the time to place a nasogastric tube before you start to ventilate would not be easy in many patients in a severe exacerbation. I would have to be convinced that there was a better outcome to go through the cost and effort to place the nasogastric tube to apply NAVA. But I agree with you theoretically that, just like the open airway in pediatric pa- 
tients, it seems the ideal place to use NAVA because it eliminates the asynchrony that we can't easily eliminate by other means.

Branson: Isn't the catheter something like $\$ 300$ ?

Kacmarek: Somewhere in the $\$ 150-\$ 200$ range.

Epstein: Rich [Branson] mentioned there might be a problem with NAVA and hyperinflation because you change the position of the diaphragm relative to the catheter, but I'm assuming that, because you're dealing with an array of electrodes, it hasn't been a problem. Has anyone looked at that issue?

Kacmarek: All of the NAVA applications have been short and none have addressed the issue of misplacement. I've got to believe the catheter moves and that you need to reassess it every few hours to make sure it's in the right place. No studies have addressed that practical issue.

Parthasarathy: One of the advantages of PAV and NAVA is that they're controlled by the patient, but that could also be one of the disadvantages. You talked about whether the patient or the clinician is right. What if the patient has inherent ventilatory instability, such as a patient with heart failure who is Cheyne-Stokes breathing? If the patient is Cheyne-Stokes breathing, I wonder how NAVA and PAV function?
Kacmarek: Personally, I would not use NAVA or PAV during CheyneStokes respiration. I indicated hemodynamic instability; maybe I should have been more specific and said any cardiovascular instability where you're questioning the patient's ability to sustain an appropriate drive. Until we have data on those types of patients, I think it's best to err on the conservative side and not use NAVA or PAV on those patients.

Parthasarathy: I think NAVA with NIV is an oxymoron, because the nasogastric tube required for NAVA is invasive.

Kacmarek: I agree.

Hess: Maybe this is my hang-up, but why is it called NAVA? It's really not neurally adjusted-it's diaphragmatically adjusted ventilatory assist. I can think of cases like spinal cord injury where there would be central neural activity, but NAVA would absolutely not work.

Kacmarek: I can't answer that question, Dean, because I didn't name it.

Gentile: Bob, I'm curious how you came up with 7 days for trying this, because with PAV it's just a few buttons on the ventilator, but with NAVA you have to make the conscious decision to spend the money and put a tube in the patient. We go through the same thing with esophageal balloons when looking at trigger asynchrony, but that's invasive. When trying to ob- tain consent for a clinical trial, telling the family "We're going to put another line or tube into your loved one" gets a less than enthusiastic response. But when you say "We're going to change the ventilation mode a bit" they're much more agreeable to participating.

Kacmarek: I just made the assumption, right or wrong, that patients who are ventilated for a week are usually problematic patients. For whatever reason, they have a lot of comorbidities, and they're difficult to wean. A mode that better acclimates to the patient's demands and improves synchrony may be better.

Younes: You're not saying that you should not use it for 7 days?

Kacmarek: No. I said that any patient with an asynchrony index greater than $10 \%$ from day one would benefit from these modes. But even if the patient does not have that asynchrony index, my assumption-and I could be wrong here-is that patients who require long-term ventilation will have difficulties acclimating to the ventilator and weaning from it, and may benefit from these modes. That was my intent.

Gentile: I thought suddenly you had developed this patience where at 7 days you start looking at this. At most institutions this will be looked at from the beginning.

Kacmarek: I agree.

This article is approved for Continuing Respiratory Care Education credit. For information and to obtain your CRCE

(free to AARC members) visit

RCJournal.com 